\title{
HISTORY \\ Health activism in Cape Town: A case study of the Health Workers Society
}

\author{
W Pick, J W B Claassen, C A le Grange, G D Hussey
}

The Health Workers Society (HWS), founded in 1980, was one of several progressive health organisations that fought for a democratic health system in South Africa. We document the sociopolitical context within which it operated and some of its achievements. HWS, many of whose members were staff and students of the University of Cape Town, provided a forum for debate on healthrelated issues, politics and society, and worked closely with other organisations to oppose the apartheid state's health policies and practices. They assisted with the formation of the first dedicated trade union for all healthcare workers and were one of the first to pioneer the primary healthcare approach in an informal settlement in Cape Town.

S Afr Med J 2012;102(6):403-405.
An organised and motivated progressive health and social services movement across the country was an exciting new development in South African politics in the 1980s. This included the Health Workers Association (HWA) in the then Transvaal province, Health Workers Organisation (HWO) in Natal, Health Workers Society (HWS) in the Western Cape Province, National Medical and Dental Association (NAMDA), Democratic Nursing Organisation of South Africa (DENOSA), Organisation of Associations of Social Services of South Africa (OASSA), National Progressive Primary Health Care Network (NPPHCN) and the Health Care Trust, among others.

As part of a country-wide reactivation of anti-apartheid forces in civil society, professional and non-professional health workers formed a united front to oppose the reactionary forces within the established medical, dental and nursing associations, which continued to support the apartheid government. This health activism was part of a general upsurge of opposition to apartheid.

The emergence of progressive health organisations brought many ideological debates. NAMDA, for example, was established by doctors and dentists opposed to the Medical and Dental Associations of South Africa that played apartheid collaborationist roles. These professional associations included only doctors and dentists. Some felt that they perpetuated the distinction between professionals and non-professionals. The health-worker group of organisations (HWA, HWO and HWS) shared the view that all people involved in healthcare provision should be united against oppressive and exploitative health systems and practices. There was to be no distinction between professional and non-professional health workers, all of whom were to be politically mobilised around health issues. We describe some activities and experiences of HWS.

William Pick is Honorary Professor of the School of Public Health and Family Medicine, University of Cape Town. James Claassen (deceased) was Director of the Metro District Health Service, Provincial Government of the Western Cape. Cynthia le Grange is a medical officer at the School of Public Health and Family Medicine, University of Cape Town. Gregory Hussey is Professor of the Institute of Infectious Diseases and Molecular Medicine, and Department of Clinical Laboratory Sciences, University of Cape Town.

\section{Establishment of HWS}

The global shift away from the biomedical model in the 1970s culminated in the Alma Ata Declaration in 1978. This primary healthcare (PHC) approach raised awareness of the deficiencies of the biomedical model and emphasised the impact of sociopolitical and economic factors on the health of communities. Embracing these principles, activists at the University of Cape Town (UCT) and elsewhere responded. One intervention was the formation of HWS, which first met in Claremont, Cape Town, on 5 October 1980. Membership included staff and students, many of whom subsequently became academic leaders at UCT.

HWS was involved in a range of activities and actively collaborated with like-minded organisations. Its aims included the promotion of health, support to communities for better health, and better working and living conditions for health workers. HWS also provided a forum for debate on issues relating to health, politics and society.

\section{The KTC project}

As a small group of health activists committed to democratising health and healthcare in South Africa (SA), HWS was inspired by the health improvements in socialist and other countries. HWS aimed to demystify health, empower ordinary South Africans to take greater control of their lives, and to counter the hegemonic control that health professionals had over health and healthcare. Apart from debates, discussions, lectures and workshops to inform and educate the membership of HWS and community organisations, an ambitious community-based project was embarked upon in the Kekaza Transit Camp (KTC) informal settlement.

The people of KTC were considered 'illegals' and prohibited by law from residing in Cape Town, where they occupied an inhospitable low-lying wetland. Numerous efforts by the police to evict people, including forcibly removing them to the Transkei and Ciskei, failed to stem the flow of people to the area. The apartheid-created Bantustans could not provide sustenance for the millions in the overpopulated rural reserves, the sources of cheap labour for SA's mines and industry long before the emergence of apartheid.

The KTC Health Project, endorsed by the community and launched in 1985, involved health workers in mobilising and empowering the community. While such a small project would not necessarily reduce the burden of disease in the community, it was designed as an alternative model to the prevailing doctor-centred, hospitalbiased healthcare system. It aimed to mobilise people around health issues to oppose the apartheid regime. Funds were raised to build a 
multipurpose centre to serve as a clinic and crèche for children and provide a meeting place for community members. The clinic, staffed by volunteers from UCT and other institutions, including nurses, physiotherapists, doctors and nursing and medical students, was well attended and up to 60 sick children were treated per session. Cars ferried the very sick to the nearest hospitals as there was no ambulance service in KTC at the time.

In keeping with its aim of empowering members of the community a community health worker (CHW) training programme was embarked upon, in defiance of the law. These workers, nominated through a community consultation process, were trained, and worked in the community during the week, supported by a trained nursing sister.

In June 1986 KTC was destroyed and many lost their lives during an orchestrated attack by witdoeke (vigilantes), aided and abetted by the police and the army. ${ }^{1}$ The clinic was burnt down, together with most of the homes. Thousands of people were displaced and temporary accommodation was provided in schools, churches and other halls throughout the peninsula. HWS was centrally involved in the care of families in three of these refugee centres. Many months after the attack, survivors moved back and the community of KTC was slowly reconstructed. A site was allocated for a new multipurpose centre which was used by the community for a range of activities including adult educational activities, and as a clinic, crèche and meeting place.

\section{Unionisation of health workers}

HWS was involved in establishing a union for health workers, who by law were not allowed to belong to a trade union. In 1980 HWS initiated discussions with local trade unions about organising hospital workers; this was unsuccessful. In 1983 HWS set up an advice office to support health workers to deal with their day-to-day problems and to provide information about conditions of employment and workers' rights. Legal support was provided by the Legal Resources Centre.

Following a strike by Groote Schuur Hospital (GSH) workers in August 1984, when public sector strikes were illegal, the GSH Health Workers Association (GSH HWA) was established in October 1985 'to provide a forum for hospital workers in which to discuss and express an opinion on events in the hospital and in our communities'. Some were also HWS members. The link between the plight of hospital workers and the difficulties experienced in communities was clearly recognised.

The Health Workers Union (HWU) was launched on 10 December 1985. The inaugural meeting was attended by 55 representatives from 9 private and public hospitals in Cape Town. This was a historic occasion as it was the first South African union catering for all health workers. Many challenges were faced in trying to organise workers. Access to hospitals for union organisers remained difficult; meetings often had to be held in workers' homes or at the union offices. Management and security personnel were obstructive, and workers were intimidated and threatened with dismissal if they wanted to join the union. Management at some institutions unsuccessfully tried to set up their own workers' committees. It was difficult to get recognition agreements signed with private hospitals as employers contested workers' right to strike. By December 1987 the union was active in 26 institutions and workers were more confident in defending their rights in the face of obstruction by management.

On 27 June 1987 the National Education, Health and Allied Workers Union (NEHAWU) was launched. NEHAWU, which was affiliated to the Congress of South African Trade Unions (COSATU), organised workers in the education, health, government and social welfare sectors. At that stage the HWU, based in Cape Town, decided not to affiliate to NEHAWU, as the members preferred to be part of the non-aligned and non-sectarian independent union movement.
HWU's non-aligned position allowed it to actively participate in collective activities, including strike action, with other unions. A significant strike in the health sector occurred in the early 1990s which resulted in formal recognition of worker rights. In $1998 \mathrm{HWU}$ membership resolved to amalgamate with like-minded groups to form the new National Union of Public Service and Allied Workers Union.

\section{Unity in action}

Despite organisational and ideological differences the progressive health organisations united around issues of racism, oppression and exploitation, particularly within the health sector.

An international event that provoked collaborative activism around health was the membership of the Medical Association of South Africa (MASA) of the World Medical Association (WMA). MASA was forced to resign in the late 1970s, because of their failure to address human rights abuses in SA and in particular the death in detention of Steve Biko. ${ }^{2}$ In 1981, supported by the conservative American Medical Association (AMA), MASA sought readmission to the WMA. ${ }^{3}$ In September 1981 a memorandum signed by 14 progressive health-worker organisations from SA, including HWS, was sent to the WMA urging them not to re-admit MASA, citing MASA's role in the Biko affair and in upholding segregated and unequal healthcare in SA. ${ }^{2}$ It also demanded a commitment to non-racial and democratic health services in SA, working for the elimination of all forms of racism and discrimination in hospitals, and the implementation of the UN Declaration of Human Rights. These demands were supported by international groups such as the Anti-Apartheid Movement in the UK. MASA was nevertheless admitted to the WMA on 3 October 1981. In protest several medical associations including those from Sweden, Canada, The Netherlands and Great Britain resigned. The WMA was invited to host their triennial conference in SA in October 1985. However, the National Committee of Health Organisations (NCOHO) was formed in Durban in December 1984 to call for the boycott of the conference. The WMA abandoned its plan to meet in SA and the conference was held in Belgium instead. This campaign was a tremendous victory for progressive health organisations and demonstrated the power of unified action across differing organisations.

The 1980s were characterised by widespread intimidation and violence by the apartheid security forces. Peaceful marches, funerals and meetings were frequently disrupted and people were physically beaten and detained without trial. In the Western Cape progressive organisations formed the WC Emergency Services Group (ESG) whose major task was to provide emergency services at political rallies and on marches. A general practitioner group within ESG provided free medical care to victims of state-instituted violence, and a first aid training group provided on-site care during events. Emergency kits were provided to activists who did duty at rallies, marches and funerals, and health workers and activists were instructed in measures to be taken when teargas and buckshot were used by police. Members of HWS were involved in the Detainees' Parents Support Group at Cowley House, Woodstock. Parents of detainees and Robben Island prisoners were housed while visiting their loved ones. Often they had no idea where their family members were detained and Cowley House became a source of such information. The work was synergistic with the work of the Detainees Treatment Team (DTT), formed in 1984, when it was attached to the Detention Action Committee. This organisation provided support for detainees and their families through the Crisis Relief Centre, which later relocated to Ledger House in Athlone. While support was mainly psychological (counselling), some practical measures were also taken. 
Lay counsellors were trained who provided enormous support to the victims and their families. The organisation also mobilised legal representation for those arrested, and lawyers (and others) provided legal services voluntarily, a sign of the extraordinary unity among the oppressed.

\section{Formation of South African Health and Social Services Organisation}

A challenge that faced the many organisations, including HWS, was finding a political direction that did not compromise its view of the social nature of health. The groundswell of political opposition to apartheid saw the emergence of a number of health and health-related organisations. Given its mission to conscientise health workers, it was necessary for the organisation to navigate its way through a myriad of 'tendencies'. A committee was established to investigate the political affiliations to which health workers could be subject. Representatives of the different 'tendencies' were invited to address the organisation and, after much debate, it was resolved that the non-aligned, nonsectarian position was correct. This had positive and negative effects. On the one hand, HWS could participate in many forums where it could influence ideas and events; on the other hand, it was not part of the main congress-aligned movement. Its two allies, HWA and HWO, aligned themselves politically with the congress movement, and later (5 March 1988) formed the South African Health Workers Congress (SAHWCO). However, despite the differences in strategies and tactics, all organisations were committed to unity in the struggle against apartheid and after much debate, the South African Health and Social Services Organisation (SAHSSO) was formed on 4 July 2002. The organisation was launched at the University of the Witwatersrand where Mr Nelson Mandela was the keynote speaker. The founding membership comprised NAMDA, SAHWCO, HWS, OASSA and the Overseas Medical Graduates Association. The NPPHCN did not join but worked closely with the organisation, especially on policy issues relating to the restructuring of health in the new democratic SA.

SAHSSO membership played a key role in mapping out the future for health policy and practice in SA. Many of the activists subsequently went into government, and while this was a disadvantage to the progressive health movement, it was beneficial in placing persons who shared its vision in positions where they could influence national and regional health policy. SAHSSO as a formal organisation no longer exists but its ideas live on in other organisations such as the Treatment Action Committee.

\section{Conclusion}

These activists' ideals, typical of many similar organisations, have become accepted. Their commitment to PHC presaged its emergence as the framework for SA's healthcare system in the 21st century, illustrated by the national policy of re-engineering of PHC and the recommendation by the National Planning Commission that CHWs form the frontline of health development. However, the implementation of the vision is more difficult than activists of the 1980s thought - many challenges remain.

How then can UCT respond to the national democratic ideals which fuelled and inspired the health activists in the 1980s? Many of SA's 1980s health problems continue. How should the Faculty of Health Sciences at UCT respond to these challenges? As the Faculty enters its second century, it seems appropriate that the relationship between its vision and actions be scrutinised. To what extent do its academic endeavours reflect the health vision of the 1980s activists and to what extent are they shared by progressive health institutions today? How can, and will, the Faculty address areas of dissonance between the academic and a progressive vision for health and healthcare in SA? These are some of the questions to reflect upon.

Acknowledgements. We acknowledge all health workers who contributed to the democratisation of health in the country and thank HWS members for their constructive comments in preparing this document.

1. Haysom N. Vigilantes: a contemporary form of repression. University of the Witwatersrand,
Johannesburg, South Africa, 25 May 1989. Paper presented at the Centre for the Study of Violence and
Reconciliation, Seminar No. 4, 25 May 1989.
2. Wright CH. Opposition to the World Medical Association Assembly in South Africa. Journal of the
National Medical Association 1985;78:541-542.
3. Hoffenberg R. Medical involvement in torture. J Med Ethics 1993;19:133-134.
4. The South African Health \& Social Services Organisation: a united health organisation is born. Critical
Health, 1992. http://www.disa.ukzn.ac.za/webpages/DC/ChJul92.1024.8196.000.039.Jul1992.19/ ChJul92.1024.8196.000.039.Jul1992.19.pdf (accessed 10 January 2012). 